\title{
Recent advances in the assessment and treatment of falls in Parkinson's disease
}

\author{
Anke H Snijders, Jorik Nonnekes and Bastiaan R Bloem*
}

Address: Department of Neurology, Donders Institute for Brain, Cognition and Behavior, Radboud University Nijmegen Medical Centre, PO Box 9101, 6500 HB, Nijmegen, The Netherlands

*Corresponding author: Bastiaan R Bloem (b.bloem@neuro.umcn.nl)

FI000 Medicine Reports 2010, 2:76 (doi:I0.3410/M2-76)

This is an open-access article distributed under the terms of the Creative Commons Attribution-Non Commercial License (http://creativecommons.org/licenses/by-nc/3.0/legalcode), which permits unrestricted use, distribution, and reproduction in any medium, provided the original work is properly cited. You may not use this work for commercial purposes.

The electronic version of this article is the complete one and can be found at: http://f1000.com/reports/m/2/76

\begin{abstract}
Falls are among the most incapacitating features of Parkinson's disease. Prevention of falls requires a systematic assessment of all contributing factors (with emphasis on freezing of gait and frontal executive dysfunction), and a multidisciplinary treatment approach tailored to the specific pathophysiology of falls for each individual patient.
\end{abstract}

\section{Introduction and context}

Falls are both common and debilitating in patients with Parkinson's disease (PD). They have devastating consequences for affected individuals, often leading to injuries, secondary immobility, and reduced quality of life. Survival is reduced once falls have occurred [1], although a recent report failed to identify a relationship between falls and mortality risk in PD [2]. Falls are also important for the public health system, as the costs associated with falls and fall-related injuries are enormous. A prospective 20-year follow-up of 136 patients with newly diagnosed PD confirmed the high prevalence of falls (87\%) and resulting fractures (35\%) [3].

For the management of falls in PD, it is important to appreciate the complex and multifactorial pathophysiology. Both balance deficits and gait disorders inherent to PD can obviously lead to falls. Environmental factors such as slippery floors, loose rugs, poor lighting, or inadequate footwear may also contribute. There is an increasing awareness that freezing of gait - a sudden and episodically occurring inability to generate effective forward stepping movements - is one of the leading causes of falls, presumably because patients are caught by surprise due to the often unexpected nature of freezing events $[4,5]$. Recent work has underscored the additional importance of cognitive impairment as a key factor contributing to both falls and freezing [6,7]; falls are an issue in demented patients in particular [8]. Possible explanations for this link include more prominent dopaminergic denervation of the caudate nucleus [9] or more generalized cholinergic dysfunction [10].

Preventing falls is generally perceived as being difficult, but is not impossible. Given the complex multifactorial nature of falls and the experience in elderly nonparkinsonian populations [11], a multidisciplinary approach appears preferable, but for patients with PD this strategy is not yet backed by scientific evidence. Crucial elements in the therapeutic approach include optimizing pharmacotherapy - increasing PD medication for dopa-sensitive signs, and stopping sedative drugs and tailored physiotherapy, based on evidence-based practice guidelines.

Here, we highlight a few important new developments in this field.

\section{Recent advances \\ Assessment of the patient with falls}

Each patient deserves a careful and systematic approach to identify all contributing factors. The quest should not stop when one causative factor has been found because falls are typically multifactorial in origin. 
A recent prospective study in 101 patients with earlystage PD assessed how various measures could predict falls [12]. The best prediction was reached by combining disease-specific measures (such as PD severity and freezing of gait severity) with balance measures (such as the occurrence of symptomatic orthostatic hypotension, the Tinetti total score, and the extent of postural anterior-posterior sway). However, even this combination attained a sensitivity and specificity for predicting falls of only around $80 \%$. Including cognitive measures that are more specific may further improve these predictive scores [13], but this remains to be examined.

Particular emphasis should be placed on testing for freezing of gait - using a series of provoking tests, including rapid 360 degree turns on the spot [14] - and for frontal executive dysfunction [7]. Specific attention should be paid to fear of renewed falling as this is common in PD [15]. Fear of falling is not only a risk factor for renewed falls [16], it may also lead to secondary immobilization with all its related adverse consequences [17].

\section{Optimizing medication}

Most balance deficits are resistant to dopaminergic medication. However, gait problems - including freezing of gait - can improve with dopaminergic medication, although doses that are higher or more frequent than those typically needed to increase hand functioning may be required [18]. Recent work points to a possible role for cholinesterase inhibitors in the treatment of gait and balance deficits, both in PD $[19,20]$ and in Alzheimer's disease [21], given that many axial motor deficits may result from misbalance between central cholinergic and dopaminergic systems [10]. Sedative drugs should be stopped whenever possible.

\section{Stereotactic deep brain surgery}

It has become clear that stereotactic deep brain surgery should be reserved for patients whose gait and balance deficits are still levodopa-responsive pre-operatively. Several studies are comparing bilateral stimulation of two different targets, namely the subthalamic nucleus (STN) and the internal globus pallidus [22,23]. The initial results indicate that both approaches are effective in providing short-term relief of motor symptoms, but one study suggested internal globus pallidus stimulation may offer better long-term outcomes for gait and balance deficits [22]. This difference was not evident in the largest study, although falls after a 2-year follow-up tended to be more common after STN stimulation [23], but this requires more study. In particular, STN stimulation has been associated with a worsening of gait and balance deficits, not only in the immediate postoperative phase, but also several years after follow-up [22,24]. Adjusting the stimulation parameters (e.g., markedly lowering the stimulation frequency) may be helpful in such patients [25]. The pedunculopontine nucleus has been studied as a promising new target, specifically for gait and balance deficits, but so far the results have not been very impressive $[26,27]$.

\section{Physiotherapy}

The evidence-based guidelines on physiotherapy for PD were recently updated [28], providing a menu of treatment modalities to improve mobility and reduce falls. Examples of evidence-based physiotherapy strategies include cueing techniques, cognitive movement strategies, and the use of exercise. Rhythmic auditory or visual cues can improve gait in PD, including freezing of gait $[29,30]$. New inventive cueing approaches include walking glasses with different patterns of visual and auditory stimulation [31] and mental singing while walking [32]. Another promising approach, especially for PD patients with freezing of gait, is the use of cycling, the skill for which can be remarkably preserved in some patients [33]. Evidence based mainly on the effects of cueing on laboratory measures of gait and balance remains; the challenge is to ascertain an enduring clinical improvement in daily life, including a reduction of falls. Fears that cues might worsen the tendency to fall - for example, by increasing overall mobility - have not been substantiated [29]. The same holds true for the effect of exercise. A systematic review concluded that exercise in patients with PD results in improvement in postural stability and balance task performance [34]. However, power and quality of exercise studies have hitherto been insufficient to make definitive recommendations. Future randomized controlled trials will look into the (cost) effectiveness of exercise to reduce falls $[35,36]$.

There is a growing body of literature on the use of treadmill training for gait rehabilitation in patients with neurologic disorders in general and for patients with PD in particular. A recent Cochrane review concluded that treadmill training may help to improve gait akinesia in $\mathrm{PD}$, but the effect on falls remains unclear [37]. It also remains uncertain how long any improvements induced by treadmill training may last.

Another interesting new development is the use of robotics, which can assist PD patients in making mediolateral anticipatory weight shifts in preparation for taking a step [38]. The initial results are promising, and such new techniques now need to be implemented in situations that are more realistic to evaluate the clinical merits of these techniques in relation to everyday gait performance and falls. 
Delivering such specific physiotherapy interventions to patients with PD likely requires trained expert physiotherapists. A large cluster-randomized trial showed that a community-based professional network with trained expert physiotherapists improved the quality of physiotherapy care and reduced health care costs, but without health benefits for patients [39].

\section{Implications for clinical practice}

Asking about falls and their impact on daily functioning should be a standard part of the evaluation of patients with PD. While awaiting further evidence, neurologists should consider installing a multidisciplinary team approach to tackle the vexing problem of falls in patients with PD. Management involves a systematic search for risk factors for falling, and a subsequent multifactorial approach aimed at eliminating or alleviating all patient-related and environmental risk factors for falling. Apart from optimizing dopaminergic medication, cholinergic therapies are now beginning to enter the field of play as well. Fear of falling must be addressed, and immobilization must be avoided as long as independent movements can still be made reasonably safely. The multidisciplinary team should ideally consist of trained and experienced professionals who treat large numbers of patients. Using this integrated approach, the goal should be to at least reduce falls or perhaps prevent them altogether, restore mobility and independence, and thereby help to maintain the quality of life for patients with PD.

\section{Abbreviations}

PD, Parkinson's disease; STN, subthalamic nucleus.

\section{Competing interests}

The authors declare that they have no competing interests.

\section{Acknowledgments}

This research was supported by the Nederlandse Organisatie voor Wetenschappelijk Onderzoek (NWO or Netherlands Organization for Scientific Research) (016076352 to BB, 92003490 to AS) and by the Stichting Internationaal Parkinson Fonds (Parkinson Foundation International Fund).

\section{References}

I. Wenning GK, Ebersbach G, Verny M, Chaudhuri KR, Jellinger K, Mckee A, Poewe W, Litvan I: Progression of falls in postmortemconfined parkinsonian disorders. Mov Disord 1999, I4:947-50.

2. Matinolli M, Korpelainen JT, Sotaniemi KA, Myllylä VV, Korpelainen R: Recurrent falls and mortality in Parkinson's disease: a prospective two-year follow-up study. Acta Neurol Scand 2010, [Epub ahead of print].
3. Hely MA, Reid WG, Adena MA, Halliday GM, Morris JG: The Sydney multicenter study of Parkinson's disease: The inevitability of dementia at 20 years. Mov Disord 2008, 23:837-44.

Changes Clinical Practice

FI000 Factor 6.0 Must Read

Evaluated by Stewart Factor II Jul 2008

4. Bloem BR, Hausdorff JM, Visser JE, Giladi N: Falls and freezing in Parkinson's disease: a review of two interconnected, episodic phenomena. Mov Disord 2004, 19:87I-84.

5. Latt MD, Lord SR, Morris JG, Fung VS: Clinical and physiological assessments for elucidating falls risk in Parkinson's disease. Mov Disord 2009, 24:1280-9.

FI000 Factor 6.0 Must Read

Evaluated by David Williams 0I Sep 2009

6. Amboni M, Cozzolino A, Longo K, Picillo M, Barone P: Freezing of gait and executive functions in patients with Parkinson's disease. Mov Disord 2008, 23:395-400.

7. Yogev-Seligmann G, Hausdorff JM, Giladi N: The role of executive function and attention in gait. Mov Disord 2008, 23:329-42.

8. Allan LM, Ballard CG, Rowan EN, Kenny RA: Incidence and prediction of falls in dementia: a prospective study in older people. PLoS One 2009, 4:e552I.

9. Bartels AL, de Jong BM, Giladi N, Schaafsma JD, Maguire RP, Veenma L, Pruim J, Balash Y, Youdim MB, Leenders KL: Striatal dopa and glucose metabolism in PD patients with freezing of gait. Mov Disord 2006, 21:1326-32.

10. Bohnen NI, Albin RL: The cholinergic system and Parkinson disease. Behav Brain Res 2010, [Epub ahead of print].

II. Gillespie LD, Gillespie WJ, Robertson MC, Lamb SE, Cumming RG, Rowe $\mathrm{BH}$ : Interventions for preventing falls in elderly people. Cochrane Database Syst Rev 2009, 2:CD000340.

12. Kerr GK, Worringham CJ, Cole MH, Lacherez PF, Wood JM, Silburn PA: Predictors of future falls in Parkinson disease. Neurology 2010, 75: I16-24.

13. Thevathasan W, Aziz T: Predicting falls in Parkinson disease: a step in the right direction. Neurology 2010, 75:107-8.

14. Snijders AH, Nijkrake MJ, Bakker M, Munneke M, Wind C, Bloem BR: Clinimetrics of freezing of gait. Mov Disord 2008, 23(Suppl 2): S468-74.

15. Thomas AA, Rogers JM, Amick MM, Friedman JH: Falls and the falls efficacy scale in Parkinson's disease. J Neurol 2010, 257: | 124-8.

16. Mak MK, Pang MY: Fear of falling is independently associated with recurrent falls in patients with Parkinson's disease: a I-year prospective study. J Neurol 2009, 256:1689-95.

17. Brozova $\mathrm{H}$, Stochl J, Roth J, Ruzicka E: Fear of falling has greater influence than other aspects of gait disorders on quality of life in patients with Parkinson's disease. Neuro Endocrinol Lett 2009, 30:453-7.

18. Grimbergen YA, Speelman AD, van der Marck MA, Schoon Y, Bloem BR: Gait, postural instability and freezing. In The Nonmotor and Non-dopaminergic Features of Parkinson's Disease. Edited by Lang AE, Olanow CW, Stocchi F. Hoboken, New Jersey: Blackwell; 2010: in press.

19. Bohnen NI, Müller ML, Koeppe RA, Studenski SA, Kilbourn MA, Frey KA, Albin RL: History of falls in Parkinson disease is associated with reduced cholinergic activity. Neurology 2009, 73:1670-6.

FI000 Factor 3.2 Recommended

Evaluated by Mark Hallett I6 Dec 2009, David Brooks I2 Feb 2010

20. Litvinenko IV, Odinak MM, Mogil'naya VI, Emelin AY: Efficacy and safety of galantamine (reminyl) for dementia in patients with Parkinson's disease (an open controlled trial). Neurosci Behav Physiol 2008, 38:937-45. 
21. Assal F, Allali G, Kressig RW, Herrmann FR, Beauchet O: Galantamine improves gait performance in patients with Alzheimer's disease. J Am Geriatr Soc 2008, 56:946-7.

22. Moro E, Lozano AM, Pollak P, Agid Y, Rehncrona S, Volkmann J, Kulisevsky J, Obeso JA, Albanese A, Hariz MI, Quinn NP, Speelman JD, Benabid AL, Fraix V, Mendes A, Welter ML, Houeto JL, Cornu P, Dormont D, Tornqvist AL, Ekberg R, Schnitzler A, Timmermann L, Wojtecki L, Gironell A, Rodriguez-Oroz MC, Guridi J, Bentivoglio AR, Contarino MF, Romito $L$, et al:: Long-term results of a multicenter study on subthalamic and pallidal stimulation in Parkinson's disease. Mov Disord 2010, 25:578-86.

FI000 Factor 6.0 Must Read

Evaluated by Daniel Tarsy I5 Mar 2010

23. Follett KA, Weaver FM, Stern M, Hur K, Harris CL, Luo P, Marks WJ Jr, Rothlind J, Sagher O, Moy C, Pahwa R, Burchiel K, Hogarth P, Lai EC, Duda JE, Holloway K, Samii A, Horn S, Bronstein JM, Stoner G, Starr PA, Simpson R, Baltuch G, De Salles A, Huang GD, Reda DJ; CSP 468 Study Group: Pallidal versus subthalamic deep-brain stimulation for Parkinson's disease. N Engl J Med 2010, 362:2077-9l.

Changes Clinical Practice

FI000 Factor 3.0 Recommended

Evaluated by Robert Ruff 09 Jun 2010

24. van Nuenen BF, Esselink RA, Munneke M, Speelman JD, van LT, Bloem BR: Postoperative gait deterioration after bilateral subthalamic nucleus stimulation in Parkinson's disease. Mov Disord 2008, 23:2404-6.

25. Moreau C, Defebvre L, Destée A, Bleuse S, Clement F, Blatt JL, Krystkowiak $P$, Devos $D$ : STN-DBS frequency effects on freezing of gait in advanced Parkinson disease. Neurology 2008, $71: 80-4$.

26. Moro E, Hamani C, Poon YY, Al-Khairallah T, Dostrovsky JO, Hutchison WD, Lozano AM: Unilateral pedunculopontine stimulation improves falls in Parkinson's disease. Brain 2010, I33:215-24

FI000 Factor 3.2 Recommended

Evaluated by Peter Brown I8 Dec 2009, Kate Watkins 30 Dec 2009

27. Ferraye MU, Debû B, Fraix V, Goetz L, Ardouin C, Yelnik J, HenryLagrange C, Seigneuret E, Piallat B, Krack P, Le Bas JF, Benabid AL, Chabardès $S$, Pollak $P$ : Effects of pedunculopontine nucleus area stimulation on gait disorders in Parkinson's disease. Brain 2010, 133:205-14.

FI000 Factor 3.0 Recommended

Evaluated by Peter Brown 23 Oct 2009
28. Keus SH, Munneke M, Nijkrake MJ, Kwakkel G, Bloem BR: Physical therapy in Parkinson's disease: evolution and future challenges. Mov Disord 2009, 24: I-I4.

29. Nieuwboer A, Kwakkel G, Rochester L, Jones D, van Wegen E, Willems AM, Chavret F, Hetherington V, Baker K, Lim I: Cueing training in the home improves gait-related mobility in Parkinson's disease: the RESCUE trial. I Neurol Neurosurg Psychiatry 2007, 78: I34-40.

30. Lim I, van Wegen E, de Goede C, Deutekom M, Nieuwboer A, Willems A, Jones D, Rochester L, Kwakkel G: Effects of external rhythmical cueing on gait in patients with Parkinson's disease: a systematic review. Clin Rehabil 2005, 19:695-7I3.

31. McAuley JH, Daly PM, Curtis CR: A preliminary investigation of a novel design of visual cue glasses that aid gait in Parkinson's disease. Clin Rehabil 2009, 23:687-95.

32. Satoh M, Kuzuhara S: Training in mental singing while walking improves gait disturbance in Parkinson's disease patients. Eur Neurol 2008, 60:237-43.

33. Snijders $A H$, Bloem BR: Images in clinical medicine. Cycling for freezing of gait. $N$ Engl J Med 2010, 362:e46.

34. Dibble LE, Addison O, Papa E: The effects of exercise on balance in persons with Parkinson's disease: a systematic review across the disability spectrum. J Neurol Phys Ther 2009, 33:|4-26.

35. Canning CG, Sherrington C, Lord SR, Fung VS, Close JC, Latt MD, Howard K, Allen NE, O'Rourke SD, Murray SM: Exercise therapy for prevention of falls in people with Parkinson's disease: a protocol for a randomised controlled trial and economic evaluation. BMC Neurol 2009, 9:4.

36. van Nimwegen M, Speelman AD, Smulders K, Overeem S, Borm G, Backx F, Bloem BR, Munneke M: Rationale and design of the ParkFit study: a randomized controlled trial to increase physical activity in patients with Parkinson's disease. Mov Disord 2009, 24(Suppl I):S284-5.

37. Mehrholz J, Friis R, Kugler J, Twork S, Storch A, Pohl M: Treadmill training for patients with Parkinson's disease. Cochrane Database Syst Rev 2010, I:CD007830.

38. Mille ML, Hilliard MJ, Martinez KM, Simuni T, Zhang Y, Rogers MW: Short-term effects of posture-assisted step training on rapid step initiation in Parkinson's disease. J Neurol Phys Ther 2009, 33:88-95.

39. Munneke M, Nijkrake MJ, Keus SH, Kwakkel G, Berendse HW, Roos RA, Borm GF, Adang EM, Overeem S, Bloem BR; ParkinsonNet Trial Study Group: Efficacy of community-based physiotherapy networks for patients with Parkinson's disease: a clusterrandomised trial. Lancet Neurol 2010, 9:46-54. 